\title{
No increase in new users of blood glucose-lowering drugs in Norway 2006-2011: a nationwide prescription database study
}

\author{
Hanne Strøm ${ }^{1 *}$, Randi Selmer ${ }^{1}$, Kåre I Birkeland ${ }^{2,5}$, Henrik Schirmer ${ }^{3,4}$, Tore Julsrud Berg ${ }^{2,5}$, Anne Karen Jenum ${ }^{5,6}$, \\ Kristian Midthjell ${ }^{7}$, Christian Berg ${ }^{1}$ and Lars Christian Stene ${ }^{1}$
}

\begin{abstract}
Background: National estimates for the occurrence of diabetes are difficult to obtain, particularly time trends in incidence. The aim was to describe time trends in prevalent and incident use of blood glucose-lowering drugs by age group and gender in Norway during 2005-2011.

Methods: Data were obtained from the nationwide Norwegian Prescription Database. We defined prevalent users of "insulins only" as individuals having no oral antidiabetic drugs (OAD) dispensed from a pharmacy during the previous 24 months or in the subsequent 12 months. Incident users had no blood glucose-lowering drugs dispensed in the previous 24 months; incident "insulins only" users also had no OAD in the subsequent 12 months.

Results: In 2011, 3.2\% of the population had blood glucose-lowering drugs dispensed, and the incidence rate was 313 per 100,000 person years. The prevalence of OAD use increased from 1.8\% in 2005 to 2.4\% in 2011; however a decreasing trend in incidence of OAD use was observed, particularly in those aged 70 years and older. In 2010, 0.64\% of the population had insulins only dispensed, with an overall incidence rate in the total population of 33 per 100,000 person years which was stable over time.

Conclusions: In this nationwide study, we found that although the prevalent use of OAD had increased in recent years, incident use was stable or had decreased. This may indicate that the increase in diabetes occurrence in Norway is levelling off, at least temporarily.
\end{abstract}

Keywords: Diabetes, Blood glucose-lowering drugs, Incidence, Prevalence, Prescription database, Norway

\section{Background}

Diabetes constitutes a major public health challenge and numerous studies suggest that the prevalence is increasing in most countries [1]. However, reliable national estimates for the occurrence of diabetes are difficult to obtain, particularly time trends in incidence. Population-based health studies have limitations, since study samples tend to have low and therefore potentially biased participation $[2,3]$. A few countries such as Denmark, Sweden and Scotland have established national diabetes registers to

\footnotetext{
* Correspondence: hanne.strom@fhi.no

'Department of Pharmacoepidemiology, Division of Epidemiology, Norwegian Institute of Public Health, P.O.Box 4404, Oslo N-0403, Norway Full list of author information is available at the end of the article
}

monitor trends in the occurrence of diabetes [4,5], but few of these have complete coverage.

While most approaches to estimating the total number with diagnosed diabetes in a population are likely to have important sources of error, data from nationwide prescription drug databases can overcome the problems with biased participation and limited sample sizes to estimate gender- and age-specific trends. All diagnosed patients with Type 1 diabetes and a large majority of patients with Type 2 diabetes in most Western countries are treated with blood glucose-lowering drugs. In European children, insulin use essentially indicates a diagnosis of Type 1 diabetes [6].

Blood glucose-lowering drugs are used for other indications than diabetes, e.g. metformin for the 

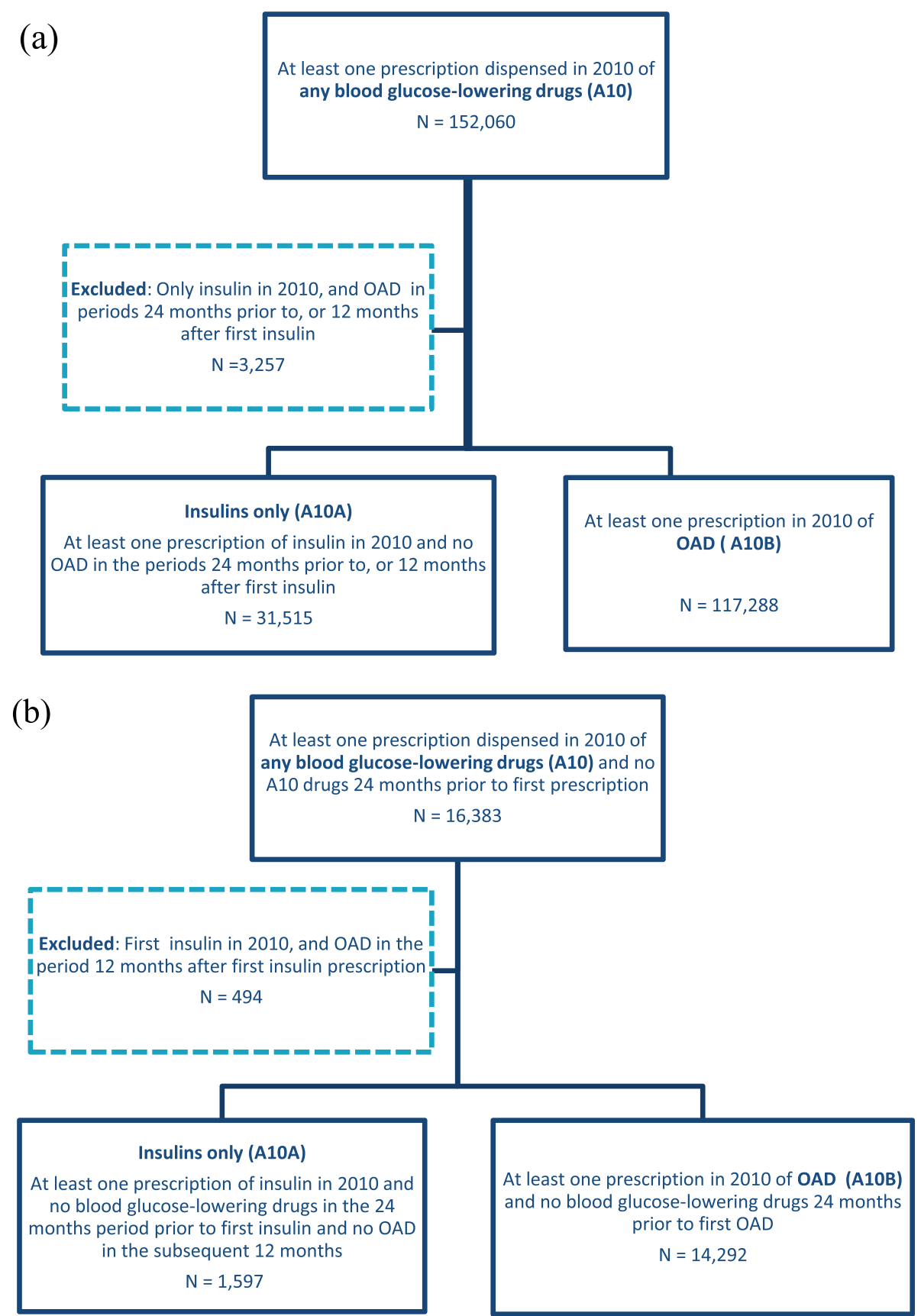

Figure 1 Flow chart illustrating the definitions used for classifying subjects as (a) prevalent and (b) incident users of any blood glucose-lowering drug, OAD and insulins only. Figures for 2010 are shown.

treatment of polycystic ovary syndrome (PCOS) and this has to be taken into account. Furthermore, diabetes not treated with blood glucose-lowering drugs and undiagnosed diabetes will not be covered but important trends can nevertheless be monitored with high quality population-based prescription databases [7].

The primary aim of this study was to describe time trends in prevalent and incident use of blood glucose-lowering drugs by age group and gender in Norway during 2005-2011.

\section{Methods}

\section{Data sources}

The Norwegian Prescription Database (NorPD) was established in 2004 and includes all prescriptions redeemed by individual patients (encrypted) at pharmacies. Information 


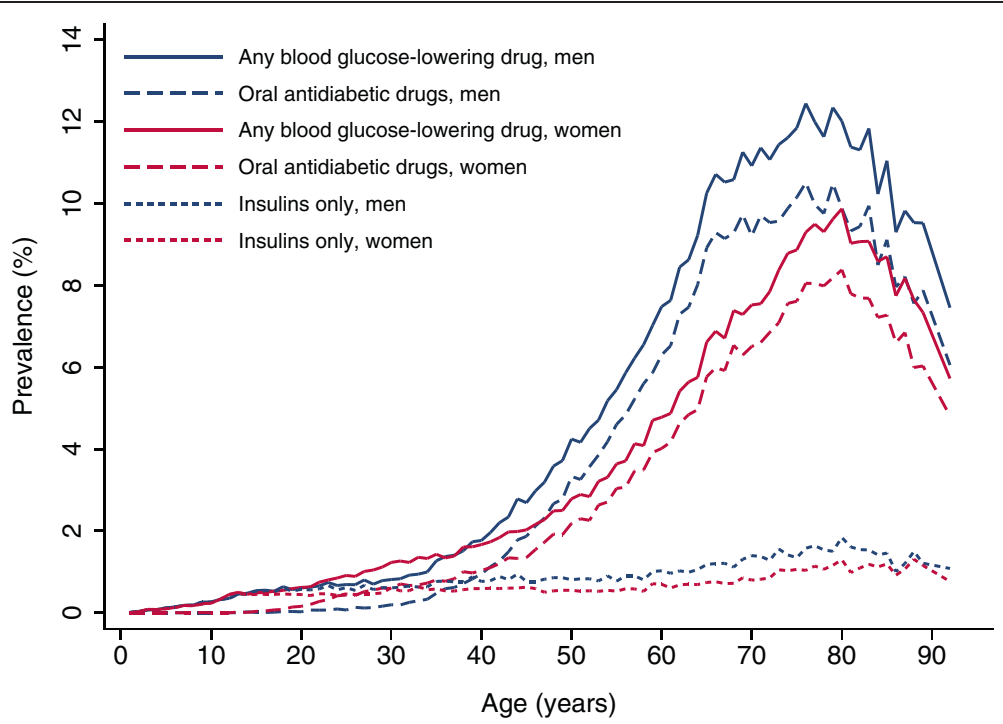

Figure 2 Prevalent use of blood glucose-lowering drugs by age and gender in Norway in 2010. Solid lines: any blood glucose-lowering drug (A10). Dashed lines, oral antidiabetic drugs. Short dashed lines: insulins only; i.e. individuals having insulins dispensed in 2010, but no OAD in the previous 24 months or in the subsequent 12 months after the first prescription filled.

on drug use in hospitals and nursing homes is collected but not on an individual level. NorPD covers drug supply for the entire population of Norway (4.92 million inhabitants in 2011). All pharmacies are obliged by law to report data electronically to the NorPD each month [8]. Blood glucose-lowering drugs are classified in the Anatomical Therapeutic Chemical (ATC) classification system in group A10. Insulins and analogues are classified in A10A, while other blood glucose-lowering drugs, referred to here as oral antidiabetic drugs (OAD), are classified in A10B $[9,10]$.

Research was part of the mandate sanctioned by the Norwegian Data Protection Authority when the NorPD was established. Permission to conduct this descriptive study was therefore not required from the Regional Committee for Medical Research Ethics.

\section{Study population}

The size of the population by gender and age in each calendar year studied was obtained from Statistics Norway. The analyses were based on data from NorPD about drugs prescribed and dispensed from 1 January 2004 to 31 December 2011. Data from 2004 were included to allow for a run-in period. Treatment with blood glucoselowering drugs was used as a proxy for drug-treated diabetes.

\section{Outcome measures}

Figure 1 illustrates the definitions used for classifying subjects as (a) prevalent and (b) incident users of any blood glucose-lowering drug, OAD and insulins only. (a) Prevalence outcome measures

Individuals with at least one prescription of any blood glucose-lowering drug dispensed in a calendar year were counted as prevalent users. Individuals with at least one OAD prescription alone or in combination with insulins dispensed in a calendar year were counted as prevalent users of OAD. Individuals with at least one prescription of insulins dispensed in a calendar year but no OAD in the periods 24 months prior to or 12 months after their first insulin prescription was dispensed were counted as prevalent users of insulins only.

\section{(b)Incidence outcome measures}

Incident users of blood glucose-lowering drugs were defined as individuals having at least one prescription of these drugs dispensed in a calendar year but not in the 24 months period prior to the first prescription. Incident users of OAD were defined as individuals having at least one prescription of OAD dispensed in a calendar year or period but no blood glucose-lowering drugs in the previous 24 months. Incident users of insulins only were defined as individuals having at least one prescription of insulin dispensed in a calendar year or period but no blood glucose-lowering drugs in the previous 24 months, and no $\mathrm{OAD}$ in the subsequent 12 months.

\section{Statistical methods}

Person years for calculation of incidence rates were estimated from the mean population size for each gender, age group and calendar year. Influence of age and gender and test for trend by calendar year were 
modelled by Poisson regression using STATA version 13 (StataCorp LP, College Station, TX, USA). Incidence rate ratio (IRR) per year was calculated, and interaction between calendar year and age was tested by likelihood ratio test.

\section{Results}

Prevalent use of blood glucose-lowering drugs

In 2011, 156,540 individuals (3.2\% of the population) had blood glucose-lowering drugs dispensed compared to 117,541 individuals (2.5\% of the population) in 2005 . As expected, the prevalence increased strongly with age. The prevalence was higher in men than in women after 40 years of age. The peak prevalence in men was at age 76 years $(12.4 \%)$ and in women at age 80 years $(9.9 \%)$, a pattern very similar to that of users of OAD (Figure 2).
The prevalence of OAD use increased from $1.8 \%$ in 2005 to $2.4 \%$ in 2011 and there was an increase in all age groups, with a larger increase in men than in women (Figure 3).

In 2010, 31,515 individuals ( $0.64 \%$ of the population) had insulins only dispensed and the prevalence was stable during the period 2006-2010 (data not shown). In a sensitivity analysis we calculated the prevalent users of insulins only by extending the period without previous use of OAD up to six years. With a six year period, the number declined to 27,927 (0.57\%) (Additional file 1: Table S1).

\section{Incident use of blood glucose-lowering drugs}

The incidence of OAD use was significantly higher in women than in men aged 20-39 years and the pattern
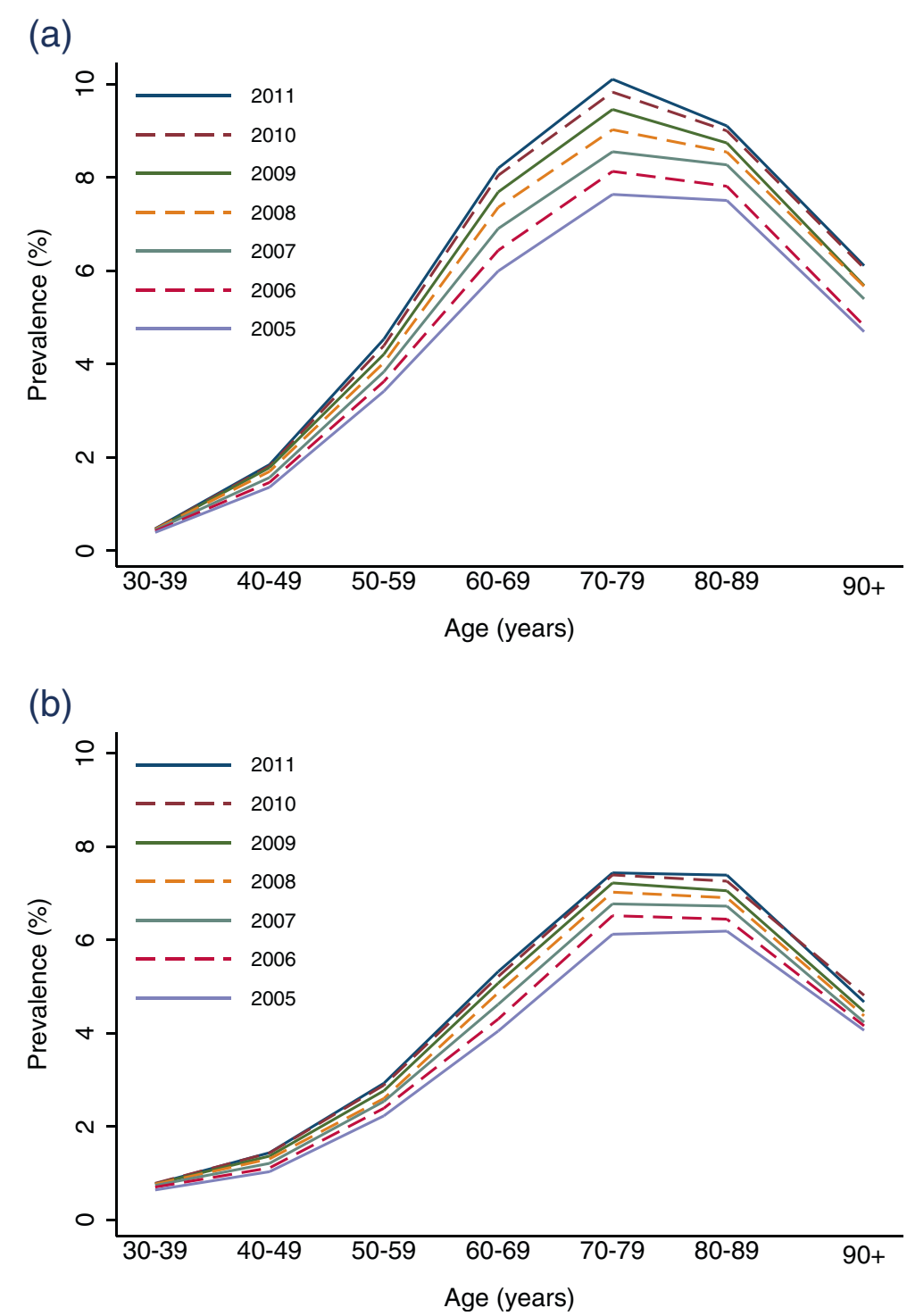

Figure 3 Time trends in prevalence of $\mathrm{OAD}(\mathrm{A} 10 \mathrm{~B})$ use by 10 year age groups in (a) men and (b) women. 


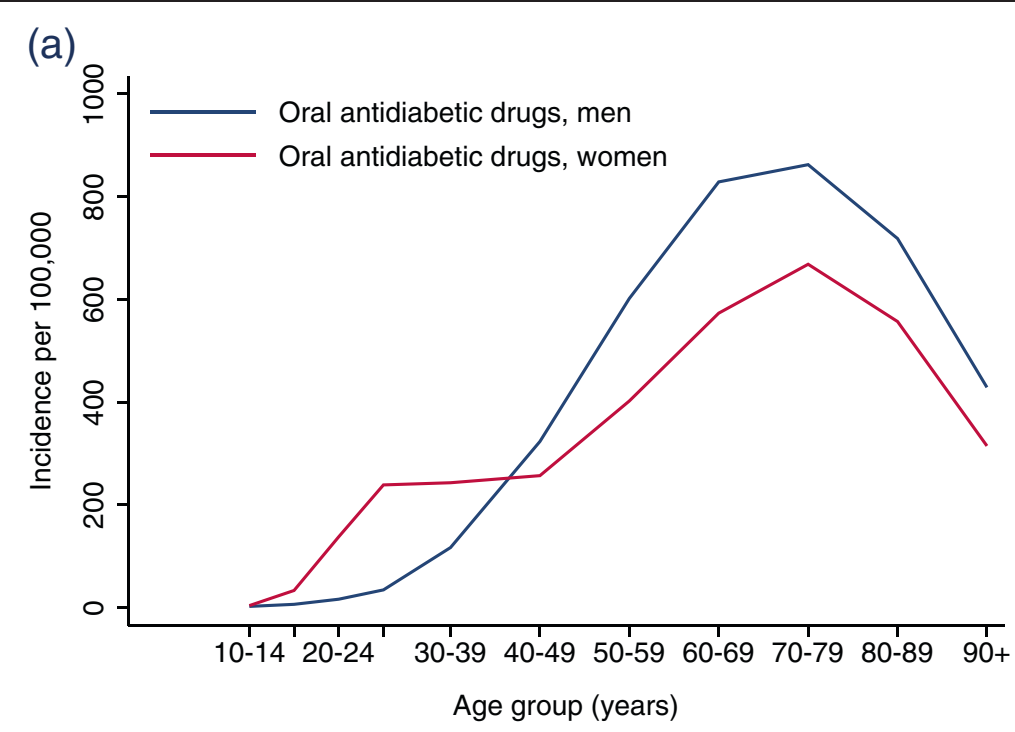

(b)

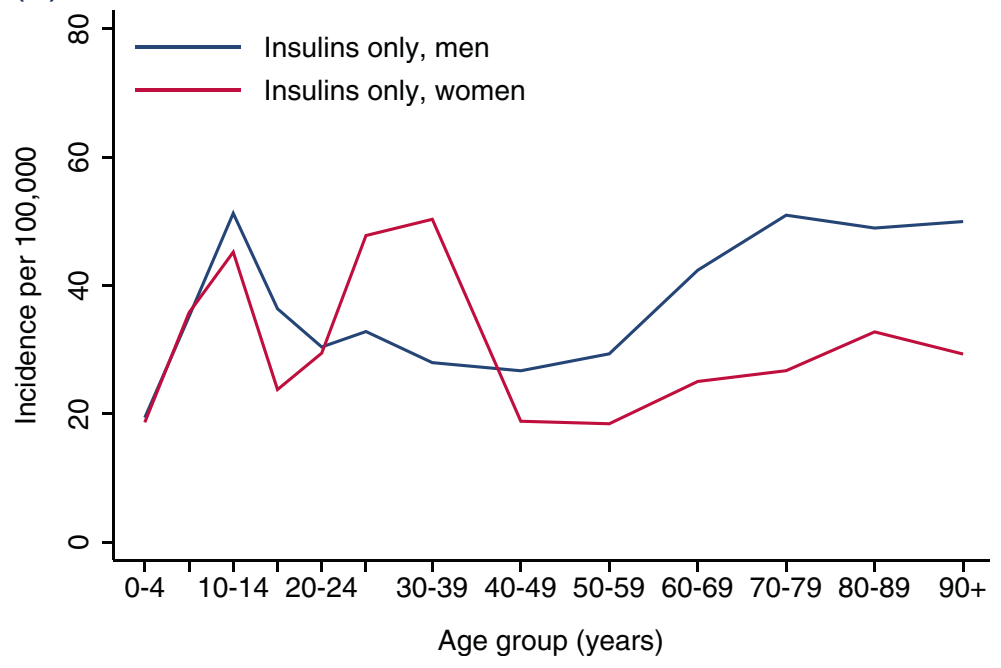

Figure 4 Incident use of blood glucose-lowering drugs by age and gender in Norway. Incident use is defined as no use of blood glucose-lowering drugs in the previous 24 months. (a) OAD (A10B); period 2006-2011. (b) Insulins and analogues (A10A); period 2006-2010. No OAD dispensed in the subsequent 12 months.

was reversed after 40 years of age (Figure 4a). In 2011, the overall incidence rate was significantly lower than the previous year (Table 1). The decreasing incidence of OAD use during the study period was largely confined to the 70 years or older age group (IRR per year $=0.97$ (95\% CI 0.96-0.98) in men and IRR = 0.95 (95\% CI 0.94-0.96) in women) but a weaker significant decreasing trend was also observed for those aged 50-69 years (IRR per year $=0.99(95 \%$ CI $0.98-1.00)$ in men and $I R R=0.98$ (95\% CI 0.97-0.99) in women) (Figures 5a-b).

In women, the highest incidence of insulin use only was in the 30-39 year age group, and for men it was highest among the 70-79 year age group (Figure $4 \mathrm{~b}$ ). In a sensitivity analysis, $59 \%$ of incident insulins only users among women aged 30-39 years in 2008 had stopped insulin treatment within the following two years, indicating gestational diabetes rather than Type 1 diabetes (Additional file 2: Figure S1). There was no significant overall time trend in incident use of insulins only for men (IRR per year $=1.01$ (95\% CI $(0.98-1.03)$ but a weak increasing overall trend for women was observed $($ IRR per year $=1.03$ (1.01-1.05) (Figures 5c-d).

\section{Supplementary material}

Detailed data tabulated by age group, gender and calendar year are provided in Additional file 1: Table S2-S5. Population sizes used to calculate incidence and prevalence are shown in Additional file 1: Table S6. 
Table 1 Incident users of any blood glucose-lowering drug, oral antidiabetic drugs (OAD) and insulins only*

\begin{tabular}{|c|c|c|c|c|c|c|c|c|c|c|}
\hline \multirow[b]{2}{*}{ Year } & \multirow[b]{2}{*}{$\begin{array}{c}\text { Person } \\
\text { years }\end{array}$} & \multicolumn{3}{|c|}{ Any blood glucose-lowering drug (A10) } & \multicolumn{3}{|c|}{ OAD (A10B) } & \multicolumn{3}{|c|}{ Insulins only (A10A only) } \\
\hline & & $\begin{array}{c}\text { No of } \\
\text { patients }\end{array}$ & $\begin{array}{c}\text { Incidence rate } \\
\text { per } 100,000 \\
\text { person years }\end{array}$ & $\begin{array}{c}95 \% \\
\text { confidence } \\
\text { interval }\end{array}$ & $\begin{array}{c}\text { No of } \\
\text { patients }\end{array}$ & $\begin{array}{c}\text { Incidence rate } \\
\text { per } 100,000 \\
\text { person years }\end{array}$ & $\begin{array}{c}95 \% \\
\text { confidence } \\
\text { interval }\end{array}$ & $\begin{array}{c}\text { No of } \\
\text { patients }\end{array}$ & $\begin{array}{c}\text { Incidence rate } \\
\text { per } 100,000 \\
\text { person years }\end{array}$ & $\begin{array}{c}95 \% \\
\text { confidence } \\
\text { interval }\end{array}$ \\
\hline \multicolumn{11}{|c|}{ Women } \\
\hline 2006 & $2,347,036$ & 7,531 & 320 & $(314,328)$ & 6,752 & 288 & $(281,295)$ & 670 & 29 & $(26,31)$ \\
\hline 2007 & $2,366,461$ & 7,769 & 328 & $(321,336)$ & 6,927 & 293 & $(286,300)$ & 679 & 29 & $(27,31)$ \\
\hline 2008 & $2,390,716$ & 7,677 & 321 & $(314,328)$ & 6,717 & 281 & $(274,288)$ & 783 & 33 & $(31,35)$ \\
\hline 2009 & $2,418,595$ & 7,832 & 323 & $(317,331)$ & 6,912 & 286 & $(279,293)$ & 745 & 31 & $(29,33)$ \\
\hline 2010 & $2,445,249$ & 7,778 & 318 & $(311,325)$ & 6,817 & 279 & $(272,286)$ & 784 & 32 & $(30,34)$ \\
\hline 2011 & $2,473,228$ & 7,269 & 293 & $(287,301)$ & 6,369 & 258 & $(251,264)$ & $\dagger$ & & \\
\hline \multicolumn{11}{|l|}{ Men } \\
\hline 2006 & $2,314,006$ & 7,829 & 338 & $(331,346)$ & 6,830 & 295 & $(288,302)$ & 756 & 33 & $(30,35)$ \\
\hline 2007 & $2,342,823$ & 8,374 & 357 & $(350,365)$ & 7,326 & 313 & $(306,320)$ & 793 & 34 & $(32,36)$ \\
\hline 2008 & $2,377,361$ & 8,655 & 364 & $(356,372)$ & 7,498 & 315 & $(308,323)$ & 845 & 36 & $(33,38)$ \\
\hline 2009 & $2,411,205$ & 8,620 & 357 & $(350,365)$ & 7,453 & 309 & $(302,316)$ & 839 & 35 & $(33,37)$ \\
\hline 2010 & $2,443,697$ & 8,605 & 352 & $(345,360)$ & 7,475 & 306 & $(299,313)$ & 813 & 33 & $(31,36)$ \\
\hline 2011 & $2,479,989$ & 8,246 & 332 & $(325,340)$ & 7,131 & 288 & $(281,294)$ & t & & \\
\hline \multicolumn{11}{|l|}{ Total } \\
\hline 2006 & $4,661,041$ & 15,360 & 329 & $(324,334)$ & 13,582 & 291 & $(287,297)$ & 1,426 & 31 & $(29,32)$ \\
\hline 2007 & $4,709,284$ & 16,143 & 342 & $(338,348)$ & 14,253 & 303 & $(298,308)$ & 1,472 & 31 & $(30,33)$ \\
\hline 2008 & $4,768,077$ & 16,332 & 342 & $(337,348)$ & 14,215 & 298 & $(293,303)$ & 1,628 & 34 & $(33,36)$ \\
\hline 2009 & $4,829,800$ & 16,452 & 340 & $(335,346)$ & 14,365 & 297 & $(293,302)$ & 1,584 & 33 & $(31,34)$ \\
\hline 2010 & $4,888,946$ & 16,383 & 335 & $(330,340)$ & 14,292 & 292 & $(288,297)$ & 1,597 & 33 & $(31,34)$ \\
\hline 2011 & $4,953,217$ & 15,515 & 313 & $(308,318)$ & 13,500 & 273 & $(268,277)$ & $\dagger$ & & \\
\hline
\end{tabular}

"Incident use is defined as no use of blood glucose-lowering drugs in the previous 24 months. In addition, for insulins only no OAD was dispensed in the subsequent 12 months.

${ }^{\dagger}$ For insulins only users there are no data for 2011 due to the definition applied, requiring a 12 month follow up period after first insulin prescription filled.

\section{Discussion}

We have monitored the use of blood glucose-lowering drugs in Norway, and found an increase in the overall prevalence from $2.5 \%$ in 2005 to $3.2 \%$ in 2011 . Interestingly, the number of new users was, for the first time in the period, significantly lower in 2011 than the year before and this was primarily due to a reduction in incident use of $\mathrm{OAD}$ in the 70 years and older age groups.

The prevalence of diabetes depends on the incidence and mean duration of the disease, both of which are affected by several factors. For example, increased survival among those with the diagnosis will increase the prevalence [11] and higher life expectancy (ageing) in the general population could influence the incidence. Others have shown that declining mortality among patients may contribute, but that increasing incidence was the main driver of the increasing prevalence over time, at least in Denmark 1992-2003 [7] and in Scotland 1993-2004 [5]. We did not have mortality data in our study but others have shown a secular decrease in mortality from ischaemic heart disease among patients with diabetes in Norway [12], suggesting that this could have contributed to the observed increasing prevalence with concurrent decline in incidence.

The strength of this study is the complete coverage of the Norwegian population [8]. NorPD should therefore provide good estimates for the number of patients with diabetes treated with blood glucose-lowering drugs $(100 \%$ reimbursed), with a few caveats that are discussed below. The study does not cover diabetes that is not treated with blood glucose-lowering medication, and classification of diabetes into Type 1 or Type 2 diabetes based on available data is difficult in the older age groups. Individuals with at least one prescription of blood glucose-lowering drugs dispensed were included but the vast majority had actually had several prescriptions. In 2010, of incident users in both groups (insulins only and OAD) recorded, 88\% redeemed more than one prescription during the following 12 months. Institutionalisation, emigration, switch to lifestyle treatment only, or off-label use (PCOS, obesity) could partly confound the results (see below). The high incident 
(a)

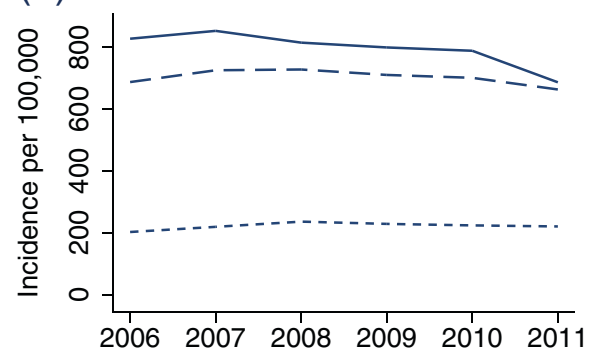

(c)

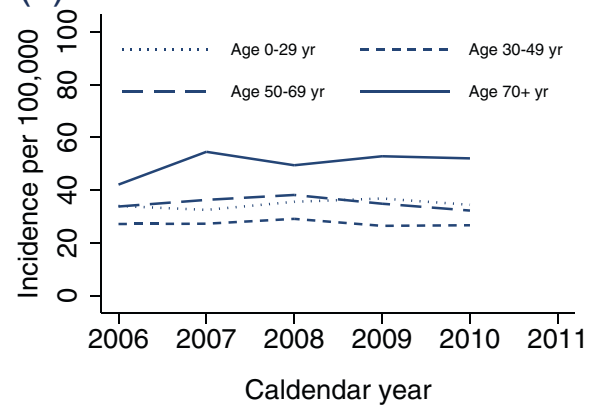

(b)

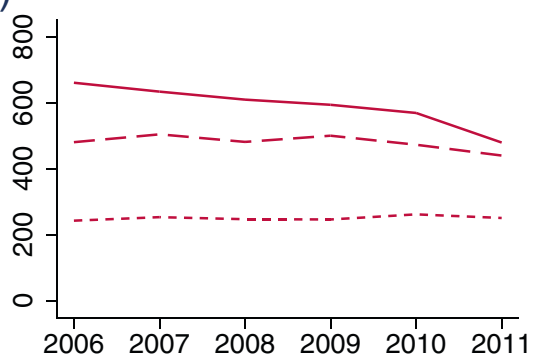

(d)

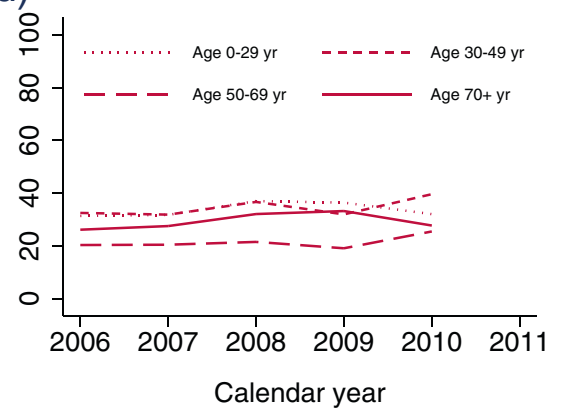

Figure 5 Time trends in incident use of blood glucose-lowering drugs in Norway. Incident defined as no use of blood glucose-lowering drugs in the previous 24 months. In addition for incident use of insulins only, no OAD dispensed in the subsequent 12 months. (a) Incident use of $\mathrm{OAD}(\mathrm{A} 10 \mathrm{~B})$ in men (b) Incident use of OAD in women. (c) Incident use of insulins only (A10A) in men (d) Incident use of insulins only in women.

use of insulins in women in reproductive age might be explained by gestational diabetes.

Another limitation is lack of individual level data of institutionalised patients with diabetes. About 13\% of the population above 80 years of age (approximately 30,000 people) lived in nursing homes in Norway in 2011 (figures from Statistics Norway, www.ssb.no). Thus, the prevalence and incidence in the oldest patient groups will be underestimated. For instance, recalculating for users of blood glucose-lowering drugs in 2011, the prevalence increased from $9.0 \%$ to $10.4 \%$ in the over 80 age group. However, data from the NorPD show that in 2011 only $2.4 \%$ of total DDDs (Defined Daily Doses) [10] prescribed of blood glucose-lowering drugs were dispensed to institutions. For insulins, 3.4\% of total DDDs prescribed were dispensed to institutions. This is probably too little to have any major influence on our observed time trends.

Migration of patients has not been taken into account in the study. In principle, a prevalent user of blood glucose-lowering drugs, moving from another country to Norway, may therefore have been mistakenly counted as an incident user. Again, this is likely to be a minor source of error, particularly for time trends.

The use of dispensed drugs in a prescription database as a proxy for diabetes will obviously result in an underestimation of the total number of patients with diabetes in the population, as a considerable proportion of Type 2 diabetes patients are treated with lifestyle measures alone. Studies from Norway in the period 1995-2005 report that $20-35 \%$ of prevalent patients are treated by diet only [13-15]. Data from 33 general practices in two representative areas of Norway showed a decline in the proportion of patients with diabetes not treated with blood glucose-lowering drugs, from $30.7 \%$ in 1995 to $28.4 \%$ in 2005 [14]. Data from the Swedish Diabetes Register show a decline in the proportion of patients with Type 2 diabetes treated with diet only from $25.3 \%$ in 2008 to $23.4 \%$ in 2011 [16]. We do not have nationally representative data on the proportion of diabetes patients not treated with blood glucose-lowering medication for our study period (2005-2011) but if there is a real decline in this proportion, it is particularly interesting that the incident use of blood glucose-lowering drugs did not increase during the study period. The proportion of patients not treated may also be influenced by the number of new blood glucose-lowering drugs available on the market promoted by the pharmaceutical industry.

On the other hand, we cannot rule out the possibility that the proportion of diagnosed Type 2 diabetes patients treated with OAD has declined during the study period; for instance, as a result of patients being diagnosed earlier and increasing focus on beneficial dietary changes. Safety concerns in the elderly regarding polypharmacy and hypoglycaemic episodes could also contribute to such a trend. 
The large majority of patients receiving OAD are likely to have Type 2 diabetes. On the other hand, there will be some misclassification from prescriptions for patients with PCOS, pre-diabetes and the metabolic syndrome [17-19]. Some women of reproductive age who are treated with metformin are probably suffering from PCOS rather than diabetes. In 2011, the total number of women in this age group treated with metformin was $3,482(0.54 \%$ in this age group population), and a total of $3,712(0.58 \%)$ received oral blood glucose-lowering drugs. In European studies, the occurrence of PCOS has been reported to be 6.5-8\% [20].

Since insulins and analogues are used by both patients with Type 1 diabetes and Type 2 diabetes, the definition applied in the outcome measure "prevalent user of insulins only" is aimed at estimating a group of patients with Type 1 diabetes. Some of the defined insulins only users may have received treatment with OAD prior to the 24 month period, as suggested in our sensitivity analysis that extends the period to six years. This could be explained by switching from OAD to insulins only e.g. due to the relative contraindication of OAD in severe heart and kidney failure. Thus, the estimated prevalence of Type 1 diabetes in the population in this study may be overestimated to some extent in the elderly.

There was a stable incidence of use of insulins only. Recent data on childhood-onset Type 1 diabetes from the Norwegian Childhood Diabetes Registry show little or no increase in the past few years, which is consistent with the current results [6]. In the only previous Norwegian study of Type 1 diabetes incidence in individuals over 15 years of age from Norway, Joner \& Søvik estimated an incidence of $17 / 100,000$ person years in the age group 15-29 years during 1978-1982 [21]. The current study showed $32 / 100,000$ person years across all age groups. In the age groups over $30-40$ years, diabetes classification becomes more challenging. It is nevertheless clear that a substantial proportion of incident Type 1 diabetes cases arise in adulthood [22].

\section{Conclusions}

There was no increase in the incident use of blood glucoselowering drugs in Norway in the period 2006-2011 and there was even a decline in the incident use of OAD, particularly in those aged 70 years and older. This occurred despite an increase in prevalent use of OAD. The prevalence and incidence of insulin use only was stable during the study period. This may indicate that the increase in diabetes occurrence in Norway is levelling off, at least temporarily.

\section{Additional files}

Additional file 1: Table S1. Effect of extending the period for: * no previous use of oral antidiabetic drugs (A10B) on estimated number of prevalent users in 2010; ${ }^{* *}$ no previous use of blood glucose-lowering drugs (A10) on estimated number of incident users in 2010. Table S2. Prevalent users of blood glucose-lowering drugs (A10) in Norway 2005-2011. Table S3. Prevalent users of oral antidiabetic drugs (A10B) in Norway 2005-2011. Table S4. Incident users and incidence rate (per 100,000 person years) of use of oral antidiabetic drugs (A10B) in Norway 2006-2011 (no A10 previous 24 months). Table S5. Incident users and incidence rate (per 100,000 person years) of insulin only use 2006-2010 in Norway (no A10 previous 24 months and no A10B 12 months after first insulin prescription dispensed). Table S6. Mean population used in calculation of incidence rates and prevalences of use of blood glucose-lowering drugs in Norway 2005-2011.

Additional file 2: Figure S1. New users of insulins only among women aged $30-39$ years in 2008 .

\section{Abbreviations}

ATC: Anatomical therapeutic chemical; DDD: Defined daily dose; NorPD: Norwegian prescription database; OAD: Oral antidiabetic drugs; PCOS: Polycystic ovary syndrome.

\section{Competing interests}

The authors declare that they have no competing interests.

\section{Authors' contributions}

HS conceived the study and drafted and edited the manuscript. KIB, HSC, $\mathrm{TJB}, \mathrm{AKJ}, \mathrm{KM}, \mathrm{CB}$ and LCS developed the design, interpreted the results and revised the manuscript. RS participated in the design of the study and performed the statistical analysis. All authors reviewed the manuscript for intellectual content and approved the final manuscript.

\section{Acknowledgments}

A working group was established by the Norwegian Diabetes Association to conduct this study. As well as the authors, the group consisted of: Geir Joner, John Cooper and Tor Claudi. We would also like to thank Liv Nordby and Bjørnar Allgot from the Norwegian Diabetes Association for co-ordination and support.

\section{Funding sources}

This work was partially funded by the Norwegian Diabetes Association.

\section{Author details}

${ }^{1}$ Department of Pharmacoepidemiology, Division of Epidemiology, Norwegian Institute of Public Health, P.O.Box 4404, Oslo N-0403, Norway. ${ }^{2}$ Department of Endocrinology, Morbid Obesity and Preventive Medicine, Oslo University Hospital, Oslo, Norway. ${ }^{3}$ Department of Clinical Medicine, University of Tromsø, Hansine Hansens veg 18, Tromsø 9019, Norway. ${ }^{4}$ Division of Heart and Lung Disease, University Hospital of North Norway, Tromsø, Norway. ${ }^{5}$ Faculty of Medicine, University of Oslo, Oslo, Norway. ${ }^{6}$ Faculty of Health, Oslo and Akershus University College of Applied Science, Oslo, Norway. ${ }^{7}$ Department of Public Health and General Practice, Norwegian University of Science and Technology, Trondheim, Norway.

Received: 13 November 2013 Accepted: 21 May 2014

Published: 29 May 2014

\section{References}

1. Shaw JE, Sicree RA, Zimmet PZ: Global estimates of the prevalence of diabetes for 2010 and 2030. Diabetes Res Clin Pract 2010, 87:4-14.

2. Morton LM, Cahill J, Hartge P: Reporting participation in epidemiologic studies: a survey of practice. Am J Epidemiol 2006, 163:197-203.

3. Eriksson AK, Ekbom A, Hilding A, Östenson CG: The influence of non-response in a population-based cohort study on type 2 diabetes evaluated by the Swedish prescribed drug register. Eur J Epidemiol 2012, 27:153-162.

4. Carstensen B, Borch-Johnsen K: Register-based studies of diabetes. Scand J Public Health 2011, 39:175-179.

5. Evans JM, Barnett KN, Ogston SA, Morris AD: Increasing prevalence of type 2 diabetes in a Scottish population: effect of increasing incidence or decreasing mortality? Diabetologia 2007, 50:729-732.

6. Skrivarhaug T, Stene LC, Drivvoll AK, Strøm H, Joner G, Norwegian Childhood Diabetes Registry: Incidence of type 1 diabetes in Norway among children aged 0-14 years between 1989 and 2012: has the incidence 
stopped rising? Results from the Norwegian Childhood Diabetes Registry. Diabetologia 2014, 57:57-62.

7. Støvring $H$, Andersen M, Beck-Nielsen $H$, Green A, Vach W: Counting drugs to understand the disease: the case of measuring the diabetes epidemic. Popul Health Metr 2007, 5:2.

8. Furu K: Establishment of the nationwide Norwegian Prescription Database (NorPD) - new opportunities for research in pharmacoepidemiology in Norway. Norwegian J Epidemiol 2008, 18:129-136 (available from: http://www.ntnu.no/ojs/index.php/norepid/article/view/23/17).

9. WHO Collaborating Centre for Drug Statistics Methodology, Guidelines for ATC Classification and DDD assignment: Os/o, 2012. WHO Collaborating Centre for Drug Statistics Methodology: Norwegian Institute of Public Health; 2013 (available from: http://www.whocc.no/filearchive/publications/ 1_2013guidelines.pdf).

10. WHO Collaborating Centre for Drug Statistics Methodology, ATC classification index with DDDs: Oslo, 2012. WHO Collaborating Centre for Drug Statistics Methodology. Norwegian Institute of Public Health; 2013 (available from: http://www.whocc.no/atc_ddd_publications/ atc_ddd_index/).

11. Ma RC, Tong PC: Epidemiology of type 2 diabetes. In Textbook of Diabetes, Volume 4. Edited by Holt Rl, Cockram CS, Flyvbjerg A, Goldstein BJ. 4 Wiley-Blackwell, Oxford; 2010:45-68.

12. Dale AC, Vatten $\sqcup$, Nilsen TI, Midthjell K, Wiseth R: Secular decline in mortality from coronary heart disease in adults with diabetes mellitus: cohort study. BMJ 2008, 337:a236.

13. Tran AT, Diep LM, Cooper JG, Claudi T, Straand J, Birkeland K, Ingskog W, Jenum AK: Quality of care for patients with type 2 diabetes in general practice according to patients' ethnic background: a cross-sectional study from Oslo. Norway BMC Health Serv Res 2010, 10:145.

14. Cooper JG, Claudi T, Jenum AK, Thue G, Hausken MF, Ingskog W, Sandberg S: Quality of care for patients with type 2 diabetes in primary care in Norway is improving: results of cross-sectional surveys of 33 general practices in 1995 and 2005. Diabetes Care 2009, 32:81-83.

15. Jenssen TG, Tonstad S, Claudi T, Midthjell K, Cooper J: The gap between guidelines and practice in the treatment of type 2 diabetes $A$ nationwide survey in Norway. Diabetes Res Clin Pract 2008, 80:314-320

16. Gudbjornsdottir S, Eliasson B, Cederholm J, Zethelius B, Svensson AM, Samuelsson P: Annual Report of the Swedish Diabetes Register, 2011 [In Swedish]. The Swedish Diabetes Register; 2012. available from: https://www.ndr.nu/pdf/NDR_rapport2011_LR.pdf.

17. Hsia Y, Dawoud D, Sutcliffe AG, Viner RM, Kinra S, Wong IC: Unlicensed use of metformin in children and adolescents in the UK. Br J Clin Pharmacol 2012, 73:135-139.

18. Mastorakos G, Lambrinoudaki I, Creatsas G: Polycystic ovary syndrome in adolescents: current and future treatment options. Paediatr Drugs 2006, 8:311-318.

19. Brufani C, Fintini D, Nobili V, Patera Pl, Cappa M, Brufani M: Use of metformin in pediatric age. Pediatr Diabetes 2011, 12:580-588.

20. Asuncion M, Calvo RM, San Millan JL, Sancho J, Avila S, Escobar-Morreale HF: A prospective study of the prevalence of the polycystic ovary syndrome in unselected Caucasian women from Spain. J Clin Endocrinol Metab 2000 85:2434-2438.

21. Joner G, Søvik O: The incidence of type 1 (insulin-dependent) diabetes mellitus 15-29 years in Norway 1978-1982. Diabetologia 1991, 34:271-274.

22. Olsson L, Ahlbom A, Grill V, Midthjell K, Carlsson S: High levels of education are associated with an increased risk of latent autoimmune diabetes in adults: results from the Nord-Trondelag health study. Diabetes Care 2011 34:102-107.

doi:10.1186/1471-2458-14-520

Cite this article as: Strøm et al: No increase in new users of blood glucose-lowering drugs in Norway 2006-2011: a nationwide prescription database study. BMC Public Health 2014 14:520

\section{Submit your next manuscript to BioMed Central and take full advantage of:}

- Convenient online submission

- Thorough peer review

- No space constraints or color figure charges

- Immediate publication on acceptance

- Inclusion in PubMed, CAS, Scopus and Google Scholar

- Research which is freely available for redistribution

Submit your manuscript at www.biomedcentral.com/submit
Ciomed Central 